\title{
Pandangan Laki-Laki Terhadap Sosialisasi Program Keluarga Berencana (KB) Di Desa Bonto Lojong Kecamatan Ulu Ere Kabupaten Bantaeng
}

\author{
Qudratullah $^{\mathrm{a} .1}$, Nurul Fitrianti ${ }^{\mathrm{b}}$ \\ ${ }^{a}$ Mahasiswa Program Doktor Dakwah dan Komunikasi \\ UIN Alauddin Makassar,90245 \\ ${ }^{b}$ Mahasiswa Program Magister Kebidanan Sekolah Pascasarjana \\ Universitas Hasanuddin, 90245 \\ Iqudratullahrustam@gmail.com
}

Riwayat Artikel:

Diterima Juli 2018

Direvisi Agustus 2018

Disetujui September 2018

\begin{abstract}
Abstrak: Sosialisasi yang tepat tentang Program KB yang dipelopori oleh BKKBN dan Bidan Puskesmas perlu dilakukan dengan terjun langsung dalam lingkungan masyarakat dan melalui media massa untuk memberikan pemahaman, informasi-informasi program KB kepada seluruh masyarakat tanpa mengenal tingkat pendidikan, agama, serta strata sosial sebagai upaya pemerintah mengentaskan kemiskinan dengan cara mempersuasi masyarakat lebih dekat agar mereka dapat mengatur perkawinan, reproduksi, jarak kelahiran, serta memiliki jumlah anak yang ideal. Kendala sosialisasi program KB kadangkala selalu ditemukan, salah satunya di Desa Bonto Lojong Kecamatan Ulu Ere Kabupaten Bantaeng, yang mana memiliki Jarak dari ibu kota kecamatan $+2,5 \mathrm{~km}$ dan jarak dari ibu kota Kabupaten $+23 \mathrm{~km}$. Jarak tempuh wilayah Desa Bonto Lojong dari Ibu kota Kabupaten Bantaeng + 35 menit. Desa Bonto Lojong memiliki luas wilayah 4.039,21 km2 dengan jumlah Penduduk 2.890 .

Penelitian ini menggunakan metode penelitian kualitatif yang bersifat deksriptif, dengan pendekatan teori persepsi disajikan secara deskritif analitik kualitatif. Dengan sumber data primer dan sekunder yang dimiliki, serta teknik pengumpulan data melalui observasi, wawancara mendalam dan dokumentasi, akan cukup digunakan untuk mencapai tujuan penelitian ini yaitu untuk menggambarkan secara konprehensif tentang berbagai pandangan masyarakat terhadap sosialisasi program KB di Desa Bonto Lojong Kecamatan Ulu Ere Kabupaten Bantaeng.

Kesimpulan dari penelitian ini di dapat bahwa laki-laki di Desa Bonto Lojong Kecamatan Ulu Ere Kabupaten Bantaeng belum pernah mendapatkan sosialisasi secara langsung dari pihak tertentu mengenai program KB sehingga pemahaman mereka tidak begitu banyak mengenai program KB. Sedangkan untuk mengenai sosialisasi iklan KB di televisi, dianggap belum efektif dan kurang berpengaruh bagi masyarakat di desa itu.
\end{abstract}

\begin{abstract}
Socialization properly of family planning (KB) programs spearheaded by BKKBN and Puskesmas's Midwives needs to be done in the community directly and through the mass media to provide understanding, information of $\mathrm{KB}$ programs to all communities without knowing the level of education, religion, and social strata, as a government efforts for alleviate poverty by closer persuading to the people so that they could regulate their marriage, reproduction, birth spacing, and have the ideal number of their children. Constraints on the socialization of $\mathrm{KB}$ programs are sometimes always found, one of which is in the village of Bonto Lojong, Ulu Ere Subdistrict, Bantaeng Regency, which has a distance from the capital of the subdistrict $+2.5 \mathrm{~km}$ and the distance from the capital of the District $+23 \mathrm{~km}$. Distance of Bonto Lojong
\end{abstract}


Kata Kunci:

Program KB,

Sosialiasasi,

Teori Persepsi

Keywords:

KB Program,

Socialization,

Perception theory
Village from Bantaeng Regency +35 minutes. Bonto Lojong Village has an area of 4,039.21 km2 with a population of 2,890.

This research uses qualitative research methods, with a perception theory and approach presented with qualitative analytical descriptive. Primary and secondary data sources that are owned, as well as data collection techniques through observation, in-depth interviews and documentation, it will be sufficient to be used to achieve the objectives of this research, namely to describe comprehensively the various views of the community towards the socialization of $\mathrm{KB}$ programs in the village of Bonto Lojong, Ulu Ere District Bantaeng.

The conclusion of this research are that men in Bonto Lojong Village, Ulu Ere Subdistrict, Bantaeng District have never received direct socialization from certain parties regarding the KB program so that their understanding is not so much about the KB program, also for the socialization of $\mathrm{KB}$ advertisements on television, it is considered ineffective and less influential for the people in the village

\section{Pendahuluan}

Keluarga berencana hadir meningkatkan kualitas hidup manusia di tingkat kampung atau yang setara melalui program kependudukan, keluarga berencana dan pembangunan keluarga serta pembangunan sektor terkait dalam rangka mewujudkan keluarga kecil berkualitas. Dengan hadirnya program keluarga berencana, diharapkan dapat meningkatkan kesejahteraan masayarakat dan memutuskan mata rantai kemiskinan. Program yang dipelopori oleh Badan Kependudukan dan Keluarga Berencana juga merupakan langkah pemerintah dalam upaya mengentaskan kemiskinan dengan cara mengatur perkawinan, reproduksi, jarak kelahiran, dan jumlah anak ang ideal.

Olehnya, perlu sosialisasi yang tepat agar program pemerintah tersebut dapat tepat sasaran, berguna dengan baik, efektif dan juga efisien. Sosialisasi yang biasanya dilakukan oleh pihak BKKBN dan juga Bidan Puskesmas dilakukan dengan terjun langsung dalam lingkungan masyarakat dengan memberikan pemahaman program KB kepada seluruh masyarakat tanpa mengenal tingkat pendidikan, agama, serta strata sosial.

Menurut David A. Goslin, sosialisasi merupakan proses belajar yang dialami seseorang untuk memeroleh pengetahuan keterampilan, nilai-nilai dan norma-norma agar dapat berpartisipasi sebagai anggota dalam kelompok masyarakat. ${ }^{1}$ Dari pengertian tersebut, dapat disimpulkan bahwa sosialisasi merupakan bagaimana seseorang didalam proses belajar, memahami, menanamkan didalam dirinya untuk memeroleh pengetahuan keterampilan, nilainilai dan norma-norma agar individu tersebut dapat diterima serta berperan aktif di dalam kelompok masyarakat.

Sosialisai program KB tidak hanya dilakukan sekadar terjun langsung kepada masyarakat, tetapi juga melalui media massa. Di antara sosialisasi yang dilakukan dengan memanfaatkan perkembangan teknologi informasi dan komunikasi yakni iklan di televisi, radio dan media cetak dan online. Selain itu, media massa juga tidak jarang digunakan dalam menyampaikan informasi-informasi terkait program KB dengan tujuan dapat mempersuasi masyarakat lebih dekat tanpa harus berinteraksi secara langsung.

Namun, sosialisasi program KB dilakukan dengan berbagai cara tidak dipungkiri memiliki keterbatasan dan juga kendala. Salah satunya masyarakat yang mampu memahami secara spesifik iklan KB di televisi dengan keterbatasan yang ada, seperti tingkat pendidikan rendah dan bahasa. Sosialisasi yang beragam perlu untuk dimaksimalkan dengan tidak memperhatikan dampak dan juga efektif serta efesiennya cara yang digunakan sehingga program yang ditawarkan dapat diserap dan diterima oleh masyarakat banyak.

\footnotetext{
${ }^{1}$ David A. Goslin dalam Ihrom, Bunga Rampai Sosiologi Keluarga (Jakarta:Yayasan Obor Indonesia,2004), h. 30
} 
Dari sosialisasi yang dilakukan oleh pihak BKKBN dan juga para Bidan Puskesmas, perlu diketahui bagaimana pandangan masyarakat terhadap sosialisasi program KB. Dalam hal ini, peneliti menentukan tempat penelitian di Desa Bonto Lojong Kecamatan Ulu Ere Kabupaten Bantaeng dengan beberapa pertimbangan, di antaranya karena berada di bagian utara Kabupaten Bantaeng dan paling ujung dengan berbatasan langsung dengan ibu kota Kecamatan Ulu Ere yaitu Desa Bonto Marannu. Jarak dari ibu kota kecamatan + 2,5 km dan jarak dari ibu kota Kabupaten $+23 \mathrm{~km}$. Jarak tempuh wilayah Desa Bonto Lojong dari Ibu kota Kabupaten Bantaeng + 35 menit. Desa Bonto Lojong memiliki luas wilayah 4.039,21 $\mathrm{km} 2$ dengan jumlah Penduduk 2.890. ${ }^{2}$

Berdasarkan latar belakang yang dibahas sebelumnya, maka rumusan masalah dalam penelitian ini adalah (1) Bagaimana gambaran umum Desa Bonto Lojong Kecamatan Ulu Ere Kabupaten Bantaeng? (2) Bagaimana pandangan masyarakat terhadap sosialisasi program KB di Desa Bonto Lojong Kecamatan Ulu Ere Kabupaten Bantaeng?

Adapun Tujuan Penelitian, berdasarkan latar belakang dan fokus penelitian, terdapat beberapa tujuan yang hendak dicapai dalam penelitian ini (1) Untuk mengetahui gambaran umum dan kehidupan masyarakat Desa Bonto Lojong Kecamatan Ulu Ere Kabupaten Bantaeng (2) Untuk mengetahui pandangan masyarakat terhadap sosialisasi program KB di Desa Bonto Lojong Kecamatan Ulu Ere Kabupaten Bantaeng

Dalam pelaksanaan Penelitian ini terdapat manfaat yang di dapat (1) Manfaat teoritis, untuk ilmu yang bersifat teoritis dan bagi studi yang bersifat ilmiah serta pengembangan ilmu pengetahuan khususnya pada disiplin ilmu Komunikasi Kesehatan (2) Manfaat praktis, diharapkan dapat menjadi bahan acuan dalam sosialisasi program KB yang lebih baik lagi.

\section{Metodologi Penelitian}

\section{A. Jenis Penelitian}

Sesuai dengan sifat permasalahan dan objek kajian, penelitian ini menggunakan metode penelitian kualitatif yang bersifat deksriptif. Hal tersebut dilakukan guna menggambarkan secara sistematis, faktual dan akurat mengenai fenomena atau masalah yang diteliti, seperti sifat-sifat individu, keadaan, gejala kelompok tertentu atau menentukan ada tidaknya hubungan antara satu gejala dengan gejala lainnya di dalam masyarakat. Penelitian kualitatif adalah penelitian yang bermaksud untuk memahami fenomena tentang apa yang dialami oleh subyek penelitian, misalnya perilaku, persepsi, motivasi, tindakan, dll, secara holistik dan dengan cara deskripsi dalam bentuk katakata dan bahasa pada suatu konteks khusus yang alamiah dan dengan memanfaatkan berbagai metode ilmiah. ${ }^{3}$ Metode deskriptif adalah pencarian fakta dengan interpretasi yang tepat. Penelitian deskriptif mempelajari masalahmasalah dalam masyarakat, tata cara yang berlalu dalam masyarakat, serta situasi-situasi tertentu termasuk tentang hubungan kegiatan-kegiatan, sikap-sikap, pandangan-pandangan, serta proses yang berlangsung dan pengaruh-pengaruh dalam fenomena. ${ }^{4}$

\section{B. Lokasi Penelitian}

Penelitian ini dilakukan di Desa Bonto Lojong Kecamatan Ulu Ere Kabupaten Bantaeng.

\section{Focus Penelitian}

Dalam penelitian ini yang menjadi focus penelitian adalah pertanyaan tentang Sosialisasi, Program Keluarga Berencana (KB) serta Pandangan itu sendiri.

\footnotetext{
2 http://pemdesbontolojong.blogspot.com/2016/12/letak-geografis.html (Diakses pada 20 Juli 2018)

${ }^{2}$ Lexy J. Moleong, Metodologi Penelitian Kualitatif (Bandung: PT. Remaja Rosda Karya, 2005), h. 6

${ }^{3}$ Sunadi Suryabrata, Metodologi Penelitian (Jakarta: PT. Remaja Rosda Karya, 2005), h. 75
} 


\section{Sasaran dan Sumber Data}

Sumber data dalam penelitian ini terdiri dari data utama atau primer dan data kedua atau sekunder. Data yang peneliti dapatkan dari informan lain hanya untuk memperkaya data yang peneliti peroleh dari data utama. Sebagaimana yang diungkapkan oleh Lofland dalam Moleong bahwa sumber data utama dalam penelitian kualitatif ialah kata-kata, dan tindakan selebihnya adalah data tambahan seperti dokumen dan lain-lain. ${ }^{5}$ Sasaran utama penelitian ini adalah masyarakat yang merupakan penduduk Desa Bonto Lojong Kecamatan Ulu Ere Kabupaten Bantaeng.

\section{E. Instrumen Penelitian}

Instrumen penelitian dalam tradisi penelitian kualitatif adalah manusia atau orang yakni peneliti sendiri dengan menggunakan alat bantu berupa catatan, tape recorder, dan camera. Sebagaimana yang disampaikan oleh Moleong bahwa orang (peneliti) sebagai instrumen memiliki senjata yang secara luwes dapat digunakannya. ${ }^{6}$

Catatan, tape recorder, dan camera hanya digunakan sebagai alat bantu dalam melakukan penelitian. Oleh karena itu, sebagai instrumen penelitian, peneliti melakukan pemahaman makna data yang peneliti peroleh di lapangan. Sebagaimana diungkapkan Danim bahwa meskipun peneliti menggunakan beberapa alat bantu dalam pengumpulan data, data-data yang dikumpulkan perlu ditunjang oleh pemahaman yang mendalam tentang makna data-data yang diperoleh. $^{7}$

\section{F. Jenis Data}

Jenis data dalam penelitian ini adalah data primer dan sekunder. Data primer berasal dari sumber yang asli dan dikumpulkan secara khusus untuk menjawab pertanyaan penelitian. ${ }^{8}$ Sedangkan data sekunder adalah data yang diperoleh lewat pihak lain, tidak langsung diperoleh oleh peneliti dari subjek penelitiannya yang biasanya berupa dokumen atau laporan. ${ }^{9}$

\section{G. Teknik Pengumpulan Data}

Teknik pengumpulan data yang digunakan dalam penelitian ini adalah (1) Observasi (2) Wawancara mendalam, merupakan metode yang banyak digunakan untuk mendapatkan infirmasi dari masyarakat. ${ }^{10}$ (3) Dokumentasi

\section{H. Teknik Analisis Data}

Berdasarkan tujuan yang ingin dicapai dalam penelitian ini, yakni menggambarkan secara konprehensif tentang berbagai pandangan masyarakat terhadap sosialisasi program KB di Desa Bonto Lojong Kecamatan Ulu Ere Kabupaten Bantaeng, maka digunkan pendekatan teori persepsi dengan menyajikan secara deskritif analitik kualitatif

\section{Hasil Penelitian}

\section{A. Gambaran Umum Desa Bonto Lojong}

\section{1) Letak Desa}

Desa Bonto Lojong adalah salah satu desa yang terletak di Kecamatan Ulu Ere yang berada di bagian utara Kabupaten Bantaeng. Jarak dari ibu kota kecamatan $+2,5 \mathrm{~km}$ dan jarak dari ibu kota Kabupaten $+23 \mathrm{~km}$. Jarak tempuh wilayah Desa Bonto Lojong dari Ibu kota Kabupaten Bantaeng + 35 menit. Desa Bonto Lojong memiliki luas wilayah 4.039,21 km2, dengan potensi alam yang sangat produktif seperti lahan pertanian, perkebunan dan hutan.

\footnotetext{
${ }^{5}$ Lexy J. Moleong, Metodologi Penelitian Kualitatif(Bandung: PT. Remaja Rosda Karya, 2005)hal 112

${ }^{6}$ Ibid, hal 9

${ }^{7}$ Sudarwan Danim, Menjadi Peneliti Kualitatif (Bandung : Pustaka Setia 2002), h. 60

${ }^{8}$ R Donald Cooper, C. William Emory, Metode Penelitian Bisnis, Alih Bahasa Gunawan, Imam Nurmawan (Jakarta : Erlangga, 1999), h. 256

${ }^{9}$ Azwar, Metode Peneltian (Yokyakarta : Pustaka Pelajar,1998), h. 91

${ }^{10}$ Fred N. Kerlinger, Fondations of Behavioral Research, (New York: Rinehart and Winston, inc, 1973), h. 269
} 
Adapun batas-batas desa sebagai berikut :

Sebelah Utara $\quad$ : Kabupaten Gowa, Kabupaten Sinjai

Sebelah Selatan $\quad$ : Desa Bonto Tannga, Desa Bonto Bulaeng

Sebelah Timur $\quad$ : Kab. Bulukumba, Desa Kayu Loe, Desa Pa’bumbungan

Sebelah Bara $\quad$ : Kab. Jeneponto, Desa Bonto Marannu

\section{2) Administrasi Desa}

Pusat pemerintahan Desa Bonto Lojong terletak di Dusun Bangkeng Bonto dan untuk menuju Kantor Desa Secara administratif Desa Bonto Lojong terbagi atas 7 Dusun dan terdiri dari 14 RK dan 25 RT.

Setiap dusun dipimpin oleh seorang Kepala Dusun dibantu oleh Ketua RK dan Ketua RT. Sistem pemerintahan yakni, Camat sebagai penyelenggara tugas umum Pemerintahan desa dan kepala desa pada dasarnya bertanggungjawab kepada masyarakat desa dan prosedur pertanggungjawaban disampaikan ke Bupati melalui Camat. Kemudian dari pada itu kepala desa bersama dengan BPD wajib memberikan keterangan laporan pertanggungjawaban kepada masyarakatnya.

\section{3) Topografi Desa}

Desa Bonto Lojong merupakan daerah pegunungan dengan ketinggian $+2.200-1500$ meter diatas permukaan laut (mdpl)

\section{4) Iklim dan Curah Hujan}

Desa Bonto Lojong memiliki iklim tropis dan dua musim yaitu musim hujan dan musim kemarau, pada musim hujan semua lahan pertanian akan di tanami beberapa jenis tanaman dan sangat cocok dengan berbagai jenis tanaman Hortikultura seperti: kol, kentang, wortel dan bawang merah dan juga tanaman jangka panjang seperti kopi cengkeh dan sekarang dikembangkan tanaman apel dan strowberry pada musim kemarau tidak semua lahan pertanian dapat di tanami karena sumber irigasinya belum merata di seluruh areal pertanian di Desa Bonto Lojong. ${ }^{11}$

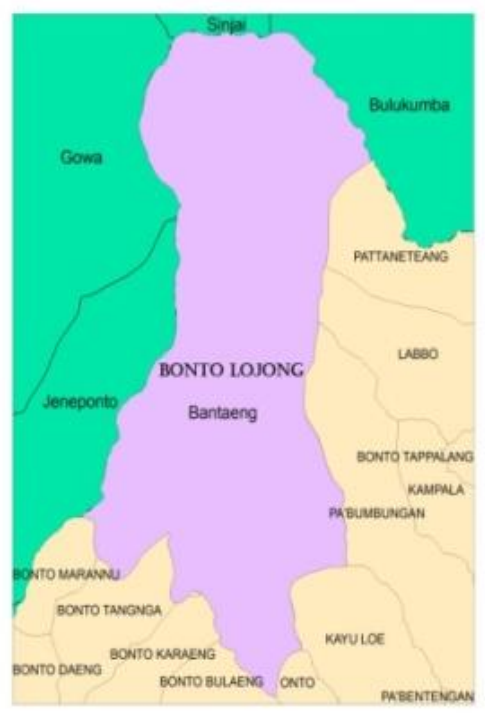

Gambar: Peta Desa Bonto Lojong

\footnotetext{
${ }^{11}$ http://pemdesbontolojong.blogspot.com/2016/12/letak-geografis.html diakses Maret 2018
} 


\section{Mata Pencaharian}

\begin{tabular}{|c|c|c|c|c|c|c|c|c|c|c|c|c|c|c|c|c|c|}
\hline \multirow{3}{*}{ No } & \multirow{3}{*}{$\begin{array}{c}\text { JENIS } \\
\text { PEKERJAAN } \\
\text { POKOK }\end{array}$} & \multicolumn{14}{|c|}{ DUSUN } & \multirow{3}{*}{ JUMLAH } & \multirow{3}{*}{$\%$} \\
\hline & & \multicolumn{2}{|c|}{ Bissawali } & \multicolumn{2}{|c|}{$\begin{array}{c}\text { Lannying } \\
2\end{array}$} & \multicolumn{2}{|c|}{$\begin{array}{c}\text { Kayu } \\
\text { Tanning }\end{array}$} & \multicolumn{2}{|c|}{$\begin{array}{c}\text { Bangkeng } \\
\text { Bonto }\end{array}$} & \multicolumn{2}{|c|}{ Lannying I } & \multicolumn{2}{|c|}{$\begin{array}{l}\text { Buakang } \\
\text { Paliang }\end{array}$} & \multicolumn{2}{|c|}{ Muntea } & & \\
\hline & & $\mathrm{L}$ & $\mathrm{P}$ & $\mathrm{L}$ & $\mathrm{P}$ & $\mathrm{L}$ & $\mathrm{P}$ & $\mathrm{L}$ & $\mathrm{P}$ & $\mathrm{L}$ & $\mathrm{P}$ & $\mathrm{L}$ & $\mathrm{P}$ & $\mathrm{L}$ & $\mathrm{P}$ & & \\
\hline 1. & Petani & 160 & 200 & 120 & 108 & 230 & 152 & 220 & 140 & 200 & 140 & 109 & 100 & 218 & 110 & 2207 & 74,6 \\
\hline 2. & PNS & 0 & 0 & 0 & 0 & 0 & 0 & 5 & 4 & 0 & 0 & 0 & 0 & 0 & 1 & 10 & 0,3 \\
\hline 3. & Buruh Tani & 4 & 0 & 2 & 0 & 1 & 0 & 2 & 0 & 0 & 2 & 0 & 0 & 4 & 0 & 15 & 0.2 \\
\hline 4. & Pedagang & 3 & 1 & 2 & 3 & 3 & 1 & 4 & 2 & 1 & 1 & 2 & 1 & 1 & 0 & 25 & 0,7 \\
\hline 5. & $\begin{array}{l}\text { Belum } \\
\text { bekerja }\end{array}$ & 52 & 42 & 61 & 100 & 47 & 50 & 50 & 50 & 50 & 18 & 40 & 51 & 30 & 77 & 718 & 24,2 \\
\hline & Jumlah & 219 & 243 & 185 & 211 & 281 & 203 & 281 & 196 & 251 & 162 & 151 & 152 & 253 & 188 & 2975 & $100 \%$ \\
\hline
\end{tabular}

\section{Usia}

\begin{tabular}{|c|c|c|c|c|c|c|c|c|c|c|c|c|c|c|c|c|c|}
\hline \multirow[t]{2}{*}{$\mathrm{NO}$} & \multirow[t]{2}{*}{ UMUR } & \multicolumn{2}{|c|}{$\begin{array}{l}\text { BISSAW } \\
\text { ALI }\end{array}$} & \multicolumn{2}{|c|}{$\frac{\text { DUSUN }}{\text { LANNYING }}$} & \multicolumn{2}{|c|}{$\begin{array}{c}\text { DUSUN } \\
\text { BANGKENG } \\
\text { BONTO }\end{array}$} & \multicolumn{2}{|c|}{$\begin{array}{c}\text { DUSUN } \\
\text { LANNYING I }\end{array}$} & \multicolumn{2}{|c|}{$\begin{array}{l}\text { DUSUN } \\
\text { BUAKANG } \\
\text { PALIANG }\end{array}$} & \multicolumn{2}{|c|}{$\begin{array}{c}\text { DUSUN } \\
\text { KAYU } \\
\text { TANNING }\end{array}$} & \multicolumn{2}{|c|}{$\begin{array}{c}\text { DUSUN } \\
\text { MUNTEA }\end{array}$} & \multirow[t]{2}{*}{ TOTAL } & \multirow[t]{2}{*}{$\%$} \\
\hline & & $\mathrm{L}$ & $\mathrm{P}$ & $\mathrm{L}$ & $P$ & $\mathrm{~L}$ & $\mathrm{P}$ & $\mathrm{L}$ & $\mathrm{P}$ & $\mathrm{L}$ & $\mathrm{P}$ & $\mathrm{L}$ & $P$ & $\mathrm{~L}$ & $P$ & & \\
\hline 1 & $\begin{array}{c}0 \mathrm{~s} / \mathrm{d} \\
12 \mathrm{Bln}\end{array}$ & 3 & 2 & 2 & 3 & 3 & 1 & 2 & 2 & 3 & 2 & 1 & 2 & 2 & 1 & 29 & 2,6 \\
\hline 2 & $\begin{array}{c}1 \mathrm{~s} / \mathrm{d} 6 \\
\text { Thn }\end{array}$ & 12 & $\begin{array}{l}1 \\
0\end{array}$ & 21 & 8 & 19 & 14 & 19 & 22 & 9 & 4 & 8 & 10 & 6 & 9 & 171 & 5,8 \\
\hline 3 & $\begin{array}{c}7 \mathrm{~s} / \mathrm{d} \\
15 \mathrm{Thn}\end{array}$ & 87 & $\begin{array}{l}6 \\
0\end{array}$ & 79 & 81 & 91 & 90 & 67 & 88 & 40 & 81 & 50 & 56 & 66 & 24 & 960 & 3,5 \\
\hline 4 & $\begin{array}{l}16 \mathrm{~s} / \mathrm{d} \\
25 \mathrm{Thn}\end{array}$ & 44 & $\begin{array}{l}4 \\
0\end{array}$ & 27 & 41 & 50 & 30 & 43 & 54 & 60 & 30 & 31 & 56 & 43 & 42 & 591 & 16,0 \\
\hline 5 & $\begin{array}{c}26 \mathrm{~s} / \mathrm{d} \\
45 \mathrm{Thn}\end{array}$ & 71 & $\begin{array}{l}3 \\
9\end{array}$ & 42 & 40 & 39 & 40 & 51 & 61 & 47 & 48 & 60 & 33 & 42 & 40 & 653 & 5,6 \\
\hline 6 & $\begin{array}{c}46 \mathrm{~s} / \mathrm{d} \\
59 \mathrm{Thn}\end{array}$ & 40 & $\begin{array}{l}2 \\
5\end{array}$ & 21 & 23 & 41 & 32 & 40 & 46 & 31 & 32 & 40 & 51 & 41 & 9 & 472 & 2,8 \\
\hline 7 & $\begin{array}{l}\text { 60Thn } \\
\text { Keatas }\end{array}$ & 8 & 6 & 9 & 10 & 5 & 7 & 5 & 6 & 5 & 6 & 7 & 4 & 5 & 7 & 90 & 18,7 \\
\hline Gra & ad Total & 265 & $\begin{array}{l}1 \\
8 \\
2\end{array}$ & 201 & 206 & 248 & 214 & 227 & 279 & 195 & 203 & 197 & 212 & 205 & 132 & 2966 & $100 \%$ \\
\hline Kes & $\begin{array}{l}\text { lotal } \\
\text { luruhan }\end{array}$ & \multicolumn{2}{|c|}{447} & \multicolumn{2}{|c|}{407} & \multicolumn{2}{|c|}{462} & \multicolumn{2}{|c|}{506} & \multicolumn{2}{|c|}{398} & \multicolumn{2}{|c|}{409} & \multicolumn{2}{|c|}{337} & 2966 & \\
\hline
\end{tabular}

\section{Jenis Kelamin}

\begin{tabular}{|c|c|c|c|c|c|c|c|c|}
\hline \multirow[b]{2}{*}{ Jenis } & \multicolumn{7}{|c|}{ DUSUN } & \multirow[b]{2}{*}{ TOTAL } \\
\hline & $\begin{array}{c}\text { BANGKENG } \\
\text { BONTO }\end{array}$ & $\begin{array}{c}\text { KAYU } \\
\text { TANNING }\end{array}$ & BISSAWALI & $\begin{array}{c}\text { LANNYING } \\
1\end{array}$ & $\begin{array}{c}\text { LANNYING } \\
2\end{array}$ & $\begin{array}{l}\text { BUAKANG } \\
\text { PALIANG }\end{array}$ & MUNTEA & \\
\hline Laki-laki & 239 & 186 & 200 & 111 & 322 & 195 & 166 & 1419 \\
\hline Perempuan & 320 & 164 & 183 & 206 & 308 & 160 & 206 & 1547 \\
\hline Jumlah & 559 & 350 & 383 & 317 & 630 & 355 & 372 & 2966 \\
\hline
\end{tabular}


Tingkat Pendidikan
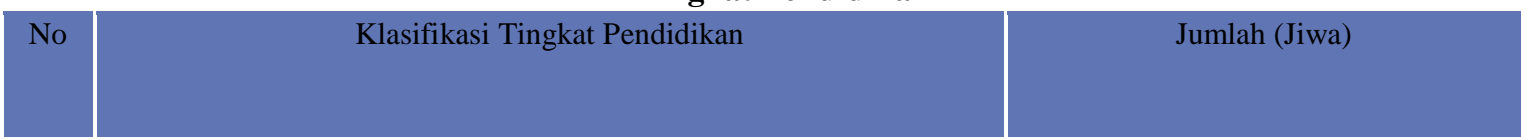

\begin{tabular}{|c|c|c|}
\hline & & \\
1 & Belum Sekolah & 153 \\
2 & Tidak Tamat SD & 1.396 \\
3 & Tamat SD / Sederajat & 607 \\
4 & Tamat SLTP / Sederajat & 64 \\
5 & Tamat SLTA / Sederajat & 78 \\
\hline 6 & Sarjana & 18 \\
\hline & Total & 2.316 \\
\hline
\end{tabular}

File Profil Desa Bonto Lojong ${ }^{12}$ Data Informan

\begin{tabular}{|c|c|c|c|}
\hline No. & Nama & Usia & Pendidikan \\
\hline 1. & Basri & 40 Tahun & SD \\
\hline 2. & Sangkala & 45 Tahun & SMA \\
\hline 3. & Jamal & 30 Tahun & SMA \\
\hline 4. & Ansar & 43 Tahun & SD \\
\hline 5. & Saring & 34 Tahun & \\
\hline
\end{tabular}

${ }^{\text {a. }}$ Sumber: Olah Data Peneliti (2018

\section{B. Pandangan Masyarakat terhadap Sosialisasi Program KB}

\section{1) Program Keluarga Berencana}

Untuk mewujudkan penduduk Indonesia yang berkualitas maka pemerintah memiliki visi dan misi baru. Visi baru pemerintah tersebut yaitu mewujudkan "Keluarga yang berkualitas". Keluarga yang berkualitas adalah keluarga yang sejahtera, sehat, maju, mandiri, mempunyai jumlah anak ideal, berwawasan kedepan, bertanggung jawab, harmonis, dan bertaqwa kepada Tuhan yang maha esa. Program KB tersebut adalah peningkatan kualitas di segala bentuk serta kesetaraan dan keadilan gender melalui pemberdayaan perempuan serta peningkatan partisipasi pria. ${ }^{13}$

KB sendiri merupakan singkatan dari Keluarga Berencana. Menurut WHO, KB adalah tindakan yang membantu individu/pasangan suami istri menghindari kelahiran yang tidak diinginkan, mendapatkan kelahiran yang diinginkan, mengatur interval di antara kehamilan, dan menentukan jumlah anak dalam keluarga. ${ }^{14} \mathrm{~KB}$ adalah sebuah sebuah metode yang betujuan untuk mengatur jumlah anak sesuai kehendak yang setiap pasangan,dan menentukan sendiri kapan seorang ibu ingin hamil. ${ }^{15}$

Secara bahasa kontrasepsi berasal dari kata kontra, berarti "mencegah" atau "melawan" dan konsepsi yang berarti pertemuan antara sel telur yang matang dan sel sperma yang mengakibatkan kehamilan. Jadi, kontrasepsi adalah menghindari terjadinya kehamilan akibat pertemuan sel telur matang dengan sel sperma. Kontrasepsi secara harfiah diartikan sebagai suatu alat atau metode yang digunakan untuk mencegah terjadinya kehamilan. ${ }^{16}$

Salah satu masalah yang menonjol dalam program keluarga berencana adalah rendahnya keikutsertaan pria/suami dalam pelaksanaan program KB. Berdasarkan data Kementerian Kesehatan RI tahun 2012, persentase peserta KB berdasarkan jenis kelamin adalah peserta perempuan mencapai $93,66 \%$ dan peserta KB laki-laki hanya berkisar 6,34\%. Dengan melihat sekilas persentase penggunaan KB terbanyak di Indonesia dapat langsung diketahui bahwa

\footnotetext{
12 https://drive.google.com/file/d/0B6YGrcFgdjEPSzVWWWFuVE82ejQ/view , diakses Maret 2018

${ }^{13}$ BKKBN, 2013.

${ }^{14}$ Ari Sulistyawati, Pelayanan Keluarga Berencana (Jakarta: Salemba Media, 2013), h. 13

${ }^{15}$ Irianto, Koes, Ilmu Kesehatan Masyarakat. Bandung; Alfabet. 2014) hal 52

${ }^{16} \mathrm{BKKBN}, 2$
} 
terjadi dominansi yang sangat besar pada penggunaan kontrasepsi perempuan dibandingkan dengan laki-laki. ${ }^{17}$

Perempuan dan laki-laki mempunyai peran dan tanggung jawab yang sama dalam meningkatkan kualitas kesehatan reproduksinya, termasuk KB dan pengasuhan anak, tetapi pada kenyataannya peran laki-laki masih rendah. Hal-hal yang sering dianggap sebagai isu gender dalam keluarga berencana sebagai berikut: a) kesetaraan ber-KB yang timpang antara laki-laki dan perempuan, ini menimbulkan anggapan bahwa dalam program KB perempuan selalu menjadi obyek/ sasaran; (b) perempuan tidak mempunyai kekuatan untuk memutuskan metode kontrasepsi yang diinginkan, antara lain karena ketergantungan pada keputusan suami, informasi yang kurang lengkap dari petugas kesehatan, penyediaan alat dan obat kontrasepsi yang tidak memadahi ditempat pelayanan; (c) pengambilan keputusan: partisipasi pria dalam program KB sangat kecil dan kurang, namun kontrol terhadap perempuan dalam hal memutuskan untuk ber KB sangatlah dominan; (d) sebaliknya ada anggapan bahwa KB adalah urusan perempuan karena kodrat perempuan untuk hamil dan melahirkan. ${ }^{18}$

Adapun bentuk partisipasi pria dalam ber-KB dapat bersifat langsung maupun tidak langsung. Partisipasi pria atau suami secara langsung dalam program KB adalah menggunakan salah satu cara atau metoda pencegahan kehamilan seperti: metode senggama terputus, metode pantang berkala, kontrasepsi kondom, vasektomi, kontrasepsi lain yang sedang dikembangkan, sedangkan bentuk partisipasi secara tidak langsung seperti (a) memilih kontrasepsi yang cocok, yaitu kontrasepsi yang sesuai dengan keinginan dan kondisi istrinya; (b) membantu pasangannya dalam menggunakan kontrasepsi secara benar, seperti mengingatkan saat minum pil KB dan mengingatkan istri untuk kontrol; (c) membantu mencari pertolongan bila terjadi efek samping maupun komplikasi; (d) mengantar istri ke fasilitas pelayanan kesehatan untuk kontrol atau rujukan ; (e) mencari alternatif lain bila kontrasepsi yang digunakan saat ini terbukti tidak memuaskan; (f) menggantikan pemakaian kontrasepsi bila keadaan kesehatan istri tidak memungkinkan; (g) membantu menghitung waktu subur, apabila menggunakan metode pantang berkala.

Terdapat beberapa faktor atau alasan yang menyebabkan rendahnya partisipasi dan minat pria dalam menjadi akseptor KB. Menurut BKKBN, faktor-faktor yang mempengaruhi rendahnya partisipasi pria dalam KB adalah: (a) Terbatasnya sosialisasi dan promosi KB lakilaki (b) Adanya persepsi bahwa wanita-lah yang menjadi target program KB (c) Terbatasnya akses pelayanan KB (d) Tingginya harga yang harus dibayar untuk ber-KB (e) Tidak nyaman dalam penggunaannya (misalnya kondom) (f) Terbatasnya metode kontrasepsi laki-laki (g) Rendahnya pengetahuan laki-laki tentang KB (h) Kualitas pelayanan KB yang tidak memadai (i) Istri yang tidak mendukung suaminya ber-KB (j) Adanya stigmatisasi tentang KB laki-laki di masyarakat (k) Kondisi politik, sosial budaya, agama masyarakat dan komitmen pemerintah masih belum optimal dalam mendukung KB laki-laki di mana penerapan program kebijakan partisipasi laki-laki di lapangan masih belum optimal. ${ }^{19}$

\section{2) Persepsi}

Persepsi adalah asumsi atau pendapat yang dikeluarkan setelah melihat suatu objek. Lahry mendefenisikan persepsi sebagai proses yang digunakan untuk menginterpretasikan data-data sensoris. Data sensoris sampai kepada manusia melalui lima inderanya. Hasil penelitian telah mengidentifikasi dua jenis pengaruh dalam persepsi, yaitu pengaruh struktural dan pengaruh fungsional. ${ }^{20}$

Persepsi meliputi penginderaan (sensasi) melalui alat-alat indera kita (indera peraba, indera penglihat indera pencium, indera pengecap, dan indera pendengar), etensi, dan interpretasi.

\footnotetext{
${ }^{17}$ Pusat Data dan Informasi Kemenkes RI, 2014

${ }^{18}$ Ibid

${ }^{19}$ Hartini. Pandangan Tokoh Agama dan Budaya Msyarakat Terhadap Pemakaian Alat Kontrasepsi. Jurnal Keseteraan dan Keadilan Gender, Volume VI No. 2 Juni 2011, h 142-154

${ }^{20}$ Warner J. Severin dan James W. Tankard, Jr , Teori Komunikasi, Sejarah, Metode dan Terapan di Dalam Media Massa (Cet. 5; Jakarta: Kencana, 2009), h. 83
} 
Sensasi merujuk pada pesan yang dikirimkan ke otak lewat penglihatan pendengaran, sentuhan, penciuman, dan pengecapan. Reseptor inderawi mata, telinga, kulit dan otot, hidung, dan lidah adalah penghubung antara otak manusia dan lingkungan sekitar. Mata bereaksi terhadap gelombang cahaya, telinga terhadap gelombang suara, kulit terhadap temperatur dan tekanan, hidung terhadap bau-bauan, dan lidah terhadap rasa. Lalu rangsangan-rangsangan ini dikirimkan ke otak. ${ }^{21}$

Untuk lebih memahami persepsi, berikut adalah beberapa definisi lain persepsi :

Brian Fellows medefinisikan persepsi sebagai proses yang memungkinkan sesuatu organisme menerima dan menganalisis informasi. Kemudian Kenneth K. Sereno dan Edward M. Bodaken mendefinisikan persepsi sebagai rasa yang memungkinkan seseorang memperoleh kesadaran akan sekeliling dan lingkungannya. Dan Philip Goodacre dan Jennifer Follers yang mendefinisikan persepsi ssebagai proses mental yang digunakan untuk mengenali rangsangan. Serta Joseph A. De Vito yang mendefinisikan persepsi adalah proses yang menjadikan seseorang sadar akan banyaknya stimulus yang mempengaruhi inderanya. ${ }^{22}$

Dari beberapa pandangan para ahli di atas, dapat disimpulkan bahwa persepsi adalah suatu proses mental untuk mengenali rangsangan yang memungkinkan seseorang memperoleh kesadaran akan banyaknya stimulus yang mempengaruhi inderanya

Faktor-Faktor yang Mempengaruhi Persepsi

Beberapa prinsip penting mengenai persepsi sebagaimana yang diungkapkan oleh Deddy Mulyana adalah sebagai berikut:

\section{a) Persepsi berdasarkan pengalaman}

Persepsi manusia terhadap seseorang, objek atau kejadian dan reaksi mereka terhadap halhal itu berdasarkan pengalaman masa lalu mereka berkaitan dengan orang, objek, atau kejadian serupa, termasuk misalnya cara kita bekerja dan menilai pekerjaan yang baik bagi kita.

\section{b) Persepsi bersifat selektif}

Atensi sebagai bagian dari tahap persepsi dipengaruhi oleh faktor-faktor internal seperti faktor biologis (lapar dan haus), fisiologis (sehat, sakit, dan lelah), sosial budaya (pekerjaan, penghasilan, kebiasaan), dan psikologis (motivasi, pengharapan, dan keinginan).

\section{c) Persepsi bersifat dugaan}

Oleh karena itu informasi yang lengkap tidak pernah tersedia, dugaan diperlukan untuk membuat kesimpulan berdasarkan informasi yang tidak lengkap lewat penginderaan itu.

\section{d) Persepsi bersifat evaluatif}

Persepsi adalah proses kognitif psoklogis dalam diri seseorang yang mencerminkan sikap, kepercayaan, nilai, dan pengharapan untuk memaknai objek persepsi.

\section{e) Persepsi bersifat kontekstual}

Dari semua pengaruh dalam persepsi seseorang, konteks merupakan salah satu pengaruh paling kuat. Ketika seseorang melihat orang lain atau suatu objek dan kejadian tertentu, konteks rangsangan sangat memengaruhi struktur kognitif, ekspektasi dan oleh karenanya juga persepsi seseorang.

\section{f) Kategori Persepsi}

Kategori persepsi dalam diri manusia terbagi atas dua bagia yaitu persepsi terhadap lingkungan fisik dan persepsi terhadap sosial. Kedua jenis persepsi tersebut masing-masing memiliki persebadaan yang signifikan.

\footnotetext{
${ }_{21}^{21}$ Deddy Mulyana, Ilmu Komunikasi Suatu Pengantar (Cet. 12; Bandung: PT. Remaja Rosdakarya Offset, 2008), h. 181

${ }^{22}$ Ibid, hal 180
} 
Yang pertama, persepsi lingkungan fisik merupakan proses penafsiran terhadap objekobjek yang tidak bernyawa di sekitar lingkungan masyarakat. Terkadang dalam memberikan pandangan terhadap lingkungan fisik kita melakukan kekeliriuan karena indera kita biasanya menipu dan itulah yang dikatakan sebagai ilusi. Persepsi terhadap objek ini dipengaruhi oleh beberapa faktor, yaitu latarbelakang pengalaman, budaya, psikologis, dan sebagainya.

Yang kedua adalah persepsi terhadap sosial yang merupakan proses menangkap arti objekobjek sosial dan kejadian yang dialami dalam lingkungan manusia. Oleh karena itu manusia bersifat emosional, sehingga penilaian terhadap suatu objek akan mengandung resiko. Duanya akan saling memengaruhi. Setiap orang memiliki pandangan yang berbeda terhadap lingkungan sosialnya.

Poin pertama, yakni mengenai sosialisasi dan promosi KB dalam deretan faktor-faktor yang memengaruhi rendahnya partisipasi pria dalam KB, menjadi hal yang perlu diperhatikan. Beberapa informan memberikan pandangannya mengenai sosialisasi program KB di Desa Bonto Lojong Kecamatan Ulu Ere Kabupaten Bantaeng. Di antaranya Basri, tidak begitu mengetahui program KB yang ditawarkan pemerintah. Menurutnya, sosialisasi program KB belum dirasakan dampaknya karena tidak banyak dilakukan sosialisasi. ${ }^{23}$

"Kalau sosialisasi jarang sekali. Dari pihak puskesmas juga jarang ada yang lakukan sosialisasi. Saya sedikit tahu KB hanya dari istri. Jadi hanya kami yang saling memberikan pemahaman"

Sama halnya dengan Basri, Sangkala juga mengungakapkan bahwa jarangnya ia mendapatkan sosialisasi pemahaman program KB pada laki-lak. Padahal menurutnya KB sangat bagus meskipun belum begitu dalam mengetahui tujuan dari $\mathrm{KB} .{ }^{24}$

"KB itu sebenarnya bagus walaupun saya belum tahu betul tujuan dari KB itu. Bahkan kondom sering saya dengar tapi tidak diketahui bentuknya. Saya juga menganggap kalau memakai kondom dalam berhubungan suami isteri itu merupakan hal yang memalukan.

Mengenai sosialisasi langsung dari beberaa pihak, Jamal juga mengungkapkan sedikit mengetahui tentang KB tapi menyadari bahwa ia juga tidak begitu banyak tahu. Kebanyakan informasi yang didapat mengenai program KB hanya didapatkan dari informasi online dengan dukungan jaringan internet.

"Saya sedikit tahu KB, tapi tidak tahu banyak juga. Informasi tidak didapatkan dari sosialisasi langsung dari pihak BKKBN ataupun puskesma. Saya hanya mendapatkan informasi yang bersumber online dengan dukungan jaringan internet.

Selain itu, Ansar juga mengaku sering mendengar program KB tapi hanya ditujukan kepada perempuan saja. Tidak ditujukan kepada laki-laki.

"Saya sering dengar KB tapi yang saya tahu KB itu Cuma ditujukan untuk perempuan saja. Laki-laki tidak usah repot. Tapi saya tahu tujuannya KB yakni untuk mengurangi anak. Untuk kondom sendiri tidak pernah diberikan sama pihak puskesmas maupun BKKBN. Padahal saya menerima saja program KB walaupun untuk laki-laki, dan itu bukanlah sebuah hal yang memalukan. Sosialisasi dari pihak-pihak tertentu memang belum pernah saya dapatkan"

Kemudian, Saring mengaku belum paham terkait program KB dan juga belum mengemukakan bahwa ia belum pernah menerima sosialisasi dari pihak puskesmas dan BKKBN.

"Saya tidak tau apa itu KB. Sosialisasi juga tidak pernah saya dapat. Sekarang kalau mau KB saya suruh istri karena setahu saya KB itu memang untuk istri bukan suami"

\footnotetext{
${ }^{23}$ Warga Kecamatan Ulu Ere

${ }^{24}$ Warga Kecamatan Ulu Ere
} 
Dari beberapa hasil wawanacar di atas, dapat disimpulkan bahwa laki-laki di Desa Bonto Lojong Kecamatan Ulu Ere Kabupaten Bantaeng belum pernah mendapatkan sosialisasi secara langsung dari pihak tertentu mengenai program KB sehingga pemahaman mereka tidak begitu banyak mengenai program KB. Hal lain yang terungkap adalah para laki-laki menganggap KB hanya ditujukan kepada istri saja tanpa adanya $\mathrm{KB}$ untuk laki-laki minimal menggunakan kondom.

Selain sosialisasi secara langsung, para informan juga memiliki pandangan mengenai sosialisasi program KB melalui iklan layanan di televisi. Basri mengemukakan bahwa iklan televisi mengenai program KB tidak berpengaruh baginya karena tidak memahami apa yang disampaikan. Sumber informasi KB satu-satunya adalah puskesmas.

"Saya tidak begitu paham kalau iklan KB di televisi. Tidak berpengaruh menurut saya. Saya hanya dapat informasi KB di puskesmas, itupun kalau saya kebetulan berkunjung ke sana”

Bersamaan dengan hal tersebut, Saring juga mengemukakan bahwa ia tidak terpengaruh dari iklan KB untuk melakukan KB bersama istri. ${ }^{25}$

"Kalau iklan KB televisi tidak ada pengaruhnya. Saya kadang saling komunikasi saja sama istri kalau mau KB. Katanya untuk tidak punya anak dulu"

Sangkala bahkan mengaku tidak tau kalau ada iklan KB di televisi. Menur'utnya hal-hal semavam itu hanya ia dapatkan di puskesmas saja.

"Saya tidak tahu kalu ada iklan KB. Yang sata tahu informasi begitu hanya ada di puskesmas saja"

Ansar dan Jamal juga mengaku tidak terlalu memperhatikan pengaruh dari iklan KB televisi. Menurut mereka, iklan tidak ada hal yang menarik dan belum diketahui pasti manfaat penyampaiannya setelah menonton. ${ }^{26}$

Dari beberapa hasil wawancara mengenai sosialisasi iklan KB di televisi, semua informan sepakat menganggap iklan KB di televisi belum efektif dan tidak memiliki pengaruh bagi mereka dan sebagian informan menganggap puskesmas sebagai satu-satunya pusat informasi mengenai program $\mathrm{KB}$.

\section{Kesimpulan}

Dari uraian hasil penelitian yang telah dibahas sebelumnya, dapat disimpulkan bahwa lakilaki di Desa Bonto Lojong Kecamatan Ulu Ere Kabupaten Bantaeng belum pernah mendapatkan sosialisasi secara langsung dari pihak tertentu mengenai program KB sehingga pemahaman mereka tidak begitu banyak mengenai program KB. Hal lain yang terungkap adalah para laki-laki menganggap KB hanya ditujukan kepada istri saja tanpa adanya KB untuk laki-laki minimal menggunakan kondom. Sedangkan untuk mengenai sosialisasi iklan KB di televisi, semua informan sepakat menganggap iklan KB di televisi belum efektif dan tidak memiliki pengaruh bagi mereka dan sebagian informan menganggap puskesmas sebagai satu-satunya pusat informasi mengenai program KB.

\footnotetext{
${ }^{25}$ Warga Kecamatan Ulu Ere

${ }^{26}$ Warga Kecamatan Ulu Ere
} 


\section{DAFTAR PUSTAKA}

Azwar, Saifuddin. 1998. Metode Peneltian.Yokyakarta.Pustaka Pelajar.

Cooper, R Donald, C. William Emory. 1999. Metode Penelitian Bisnis, Alih Bahasa Gunawan, Imam Nurmawan.Jakarta.Erlangga.

Danim, Sudarwan. 2002. Menjadi Peneliti Kualitatif .Bandung.Pustaka Setia.

File Arsip Desa Bonto Lojong

Hartini. 2011. Pandangan Tokoh Agama dan Budaya Msyarakat Terhadap Pemakaian Alat Kontrasepsi. Jurnal Keseteraan dan Keadilan Gender, Volume VI No. 2 Juni.

Ihrom, 2004. Bunga Rampai Sosiologi Keluarga. Jakart.Yayasan Obor Indonesia

Irianto. 2014. Koes, Ilmu Kesehatan Masyarakat. Bandung; Alfabet..

Kerlinger, Fred N. 1973. Fondations of Behavioral Research. New York.Rinehart and Winston.inc.

Moleong, Lexy J. 2005. Metodologi Penelitian Kualitatif .Bandung.PT. Remaja Rosda Karya.

Mulyana, Deddy.Ilmu Komunikasi Suatu Pengantar .Cet.12. 2008. Bandung.PT. Remaja Rosdakarya Offset..

Pusat Data dan Informasi Kemenkes RI.2014.

Severin, Warner J. dan James W. Tankard, Jr. 2009. Teori Komunikasi, Sejarah, Metode dan Terapan di Dalam Media Massa.Cet. 5. Jakarta.Kencana.

Sulistyawati, Ari. 2013. Pelayanan Keluarga Berencana.Jakarta.Salemba Media.

Suryabrata. 2005. Metodologi Penelitian .Jakarta.PT. Remaja Rosda Karya. 